\title{
OS PROCEDIMENTOS DE PESQUISA CIENTÍFICA NAS PRODUÇÕES DO PÓS-DESIGN UFSC - UMA LEITURA.
}

\section{SCIENTIFIC RESEARCH PROCEDURES IN THE PRODUCTIONS OF THE POSTGRADUATE IN DESIGN UFSC - A REVIEW.}

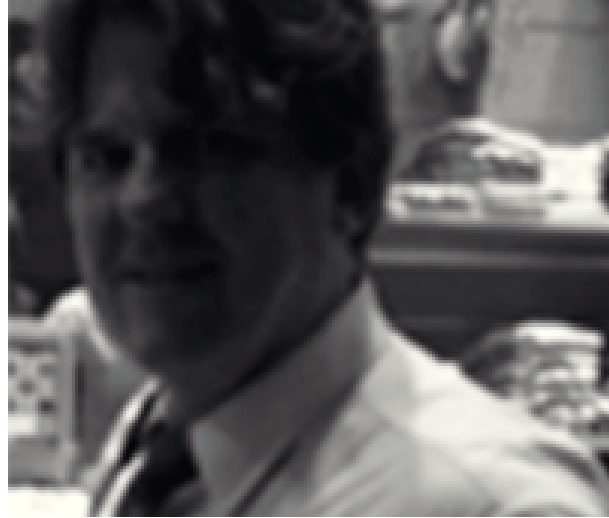

\section{Ricardo Triska}

Doutor pela Universidade

Federal de Santa Catarina.

Professor associado $1 \mathrm{da}$

Universidade Federal de Santa

Catarina, lotado no Departamento de Expressão Gráfica, compõe o quadro de Docentes Permanentes do Programa de Pós-graduação em Design e Expressão Gráfica, nível mestrado, e doutorado, e do curso de Bacharelado em Design. ricardo.triska@gmail.com

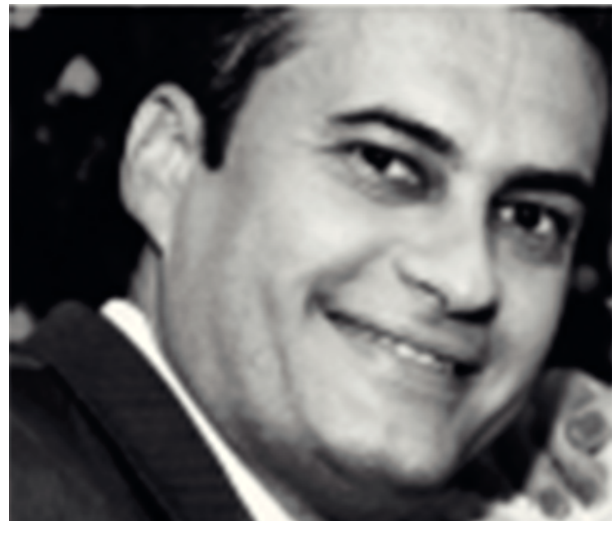

Jorge Elias Dolzan

Mestre pela Universidade do Sul de Santa Catarina.

Doutorando do Programa de Pós-Design UFSC. Bolsista da Estácio de Santa Catarina. jorge.dolzan@estacio.br

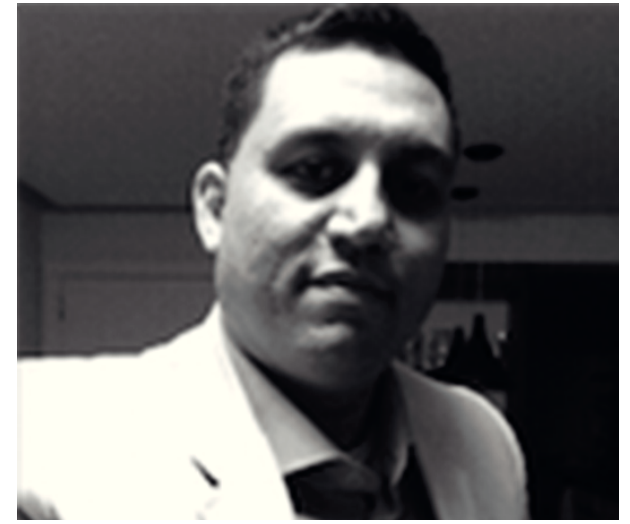

João Carlos Vela Mestre pela Universidade Regional de Blumenau. Doutorando do Programa de Pós-Design UFSC. joao.vela1@gmail.com

\section{RESUMO}

A qualificação de toda intervenção científica deriva da descrição dos procedimentos metodológicos, das ferramentas e da sistematização 
da pesquisa a ser executada. Programas de pós-graduação amadurecem a partir da evolução de seus processos de investigação e declaração dos seus princípios metodológicos. Este estudo tem como objetivo identificar os procedimentos utilizados para a investigação científica no Programa de Pós-Design-UFSC. Como método, foi utilizada a pesquisa exploratória pela coleta de dados disponíveis no site da CAPES, quantificando a produção do programa arbitrado, que permite identificar e quantifica-los sobre 0 uso de questões de pesquisa; objetivos; e hipóteses. Observou-se também se o texto continha referências claras e objetivas para os procedimentos de investigação quanto à sua classificação. No final, foi possível produzir gráficos, que proporcionam uma leitura direta e clara dos dados coletados.

\section{PALAVRAS-CHAVE}

Procedimentos de investigação científica. Metodologia. Pós-Design UFSC.

\section{ABSTRACT}

The qualification of all scientific intervention derives from the description of the methodological procedures, tools and systematization of the research to be performed. Postgraduate programs mature from the evolution of their research processes and declaration of their methodological principles.This study aims to identify the procedures used for scientific research at Pos-Design-UFSC Program. As a method, we used the exploratory research by data collection available at CAPES website, quantifying the production of the refereed program, which allows to identify and quantify them about the use of research questions; objectives; and hypotheses. It was also observed if the text contained clear and objective references to the procedures for research as to their classification. At the end it was possible to produce graphics, which provide a direct and clear reading of the collected data.

\section{KEYWORDS}

Scientific research procedures. Methodology. Pós-Design UFSC. 


\section{INTRODUÇÃO}

Os procedimentos de pesquisa são ferramentas fundamentais na obtenção de conhecimentos, na busca por diagnósticos e na compreensão de fenômenos que podem ser medidos, qualificados, quantificados e, então, publicitados visando o compartilhamento de seus resultados. Isto vale para qualquer campo do conhecimento, do senso comum ao acadêmico. Mas é neste último, que sua exigência se torna critério de aceitabilidade para concorrer à condição de conhecimento científico, este entendido como "um processo desencadeado progressivamente, em função do devir a ser, e que emerge da coexistência ou da relação entre teoria e prática, sendo que a prática é o fundamental da teoria. Esta relação condiciona o processo e a maturação do conhecimento" (Barros, 2012, p. 12).

O cenário acadêmico desta forma descortina uma especificidade do conhecimento: a científica, fruto do estimulo da investigação a partir de procedimentos sistemáticos, visando informações sobre fenômenos uma vez pesquisados e demostrados. "Não é possível realizar um trabalho científico sem a utilização dos instrumentos de pesquisa" (Fialho; Braviano; Santos, 2005, p. 25). Ao estimular a sistematização de tais procedimentos o conhecimento científico obriga a postura metódica, condição basilar de toda intervenção científica que constitui o repertório dos centros universitários e universidades, em seus programas de graduação e pós-graduação, desde sua origem. Desta forma a essência de todo e qualquer programa de pósgraduação se dá nos procedimentos sistemáticos, na definição e aplicação da metodologia científica que suporte suas pesquisas, elementos que devem nortear as ações do início ao fim de toda abordagem, de seus projetos de pesquisa, com suas intenções (questão de pesquisa, objetivos, hipóteses) às suas qualificações, defesas e publicações finais, com seus resultados explicitados de forma clara e concisa nas dissertações (quando do mestrado) e teses (quando do doutorado) disponibilizadas pelos programas como resultado de cada intervenção de seus docentes e discentes, de maneira a comprovar, formalizando sua aplicabilidade científica. Afinal a "ciência, enquanto conteúdo de conhecimentos, só se processa como resultado da articulação do lógico com o real, da teoria com a realidade" (Severino, 2002, p. 149).

De tal forma passa a ser coerente que todos os programas avaliem o que vem sendo produzido, de maneira a mensurar se os conhecimentos 
desenvolvidos pelos seus pesquisadores garantem o caráter científico, legitimado pelos procedimentos metodológicos definidos. Neste sentido este estudo parte do seguinte problema: será que todas as produções, qualificadas, defendidas e aprovadas, do Pós-Design UFSC têm questões, objetivos e hipóteses de forma clara em seus documentos finais? E será que estão claros e bem definidos seus procedimentos de pesquisa quanto a sua classificação, quanto à natureza, forma de abordagem, objetivos e procedimentos técnicos?

Este estudo tem por premissa apresentar dois objetivos, o primeiro identificar e quantificar a ocorrência de questões, objetivos e hipóteses, nas dissertações do Pós-Design UFSC; e o segundo de identificar e quantificar a ocorrência dos procedimentos de pesquisa, quanto a sua classificação, nestas mesmas produções.

Tal abordagem se justifica a medida que os interessados em ingressarem no programa de Pós-Design UFSC tenham estas produções como referências, não apenas em seus temas mas nas abordagens metodológicas que as nortearam. Da mesma forma este estudo, ao pretender ler o quantitativo dos procedimentos de pesquisa quanto a sua classificação, oferece aos alunos do próprio programa o perfil de como as pesquisas foram desenvolvidas dentro do programa. De forma mais geral esta abordagem oferece ao próprio programa uma base de dados que lidos, à luz de seu projeto pedagógico, oportuniza um avaliação dos resultados dos anos iniciais do programa de Pós-Design UFSC.

Para se alcançar os objetivos descritos, os procedimentos metodológicos deste estudo caracterizam-se quanto a natureza como básica, quanto a forma de abordagem se classificam como quantitativo, quanto aos seus objetivos é descritivo, e toma como procedimento técnicos a pesquisa bibliográfica e documental.

\section{DELIMITAÇÃO DA PESQUISA:}

Com base nos procedimentos declarados anteriormente, este estudo delimitou sua pesquisa seguindo etapas (ou passos), relatadas na sequência.

O primeiro passo foi o de tomar o Sistema Capes como base de dados a medida que a "Coordenação de Aperfeiçoamento de Pessoal de Nível Superior (Capes), fundação do Ministério da Educação (MEC), desempenha papel fundamental na expansão e consolidação da pós-graduação stricto 
sensu (mestrado e doutorado) em todos os estados da Federação" (CAPES, 2014), partindo de um banco de dados consolidado nacionalmente. Desta forma o total de produções do programa Pós-Design UFSC foi tirado da CAPES, cujo acesso se deu entre os dias 05 e 20/Jun./2014. As datas das produções tem como limite o ano de 2012 e totalizam 52 produções, mais especificamente dissertações, considerando que o doutorado abriu sua primeira turma em 2013, e ainda não tem produções defendidas e aprovadas.

O segundo passo da pesquisa foi o de buscar o acesso às 52 produções publicitadas pela Capes dentro da Biblioteca Universitária - BU da UFSC, pelo Pergamum. Nesta busca apenas 47 produções foram acessadas no formato .pdf (portable document format), sendo que em uma faltavam as páginas iniciais. Das 5 que faltaram, buscou-se no banco de dados da UFSC - https:// repositorio.ufsc.br; onde obteve-se acesso às 5 que faltavam somando a dissertação que tinha páginas faltando no Pergamum, BU-UFSC. Desta forma conseguiu-se acesso aos textos finais das 52 produções publicitadas pelo CAPES do programa do Pós-Design UFSC.

O terceiro passo foi ler os textos visando identificar e quantificar cada produção em dois blocos de informações de acordo com os objetivos pretendidos deste estudo: no primeiro identificar se nos textos havia: Questão de pesquisa; Objetivos; e Hipóteses; e no segundo, se o texto fazia referencia clara e objetiva aos procedimentos de pesquisa quanto à sua classificação: Quanto a natureza - Básica ou Aplicada; Quanto a sua forma de abordagem - Qualitativa ou Quantitativa ou Qualitativa-quantitativa; Quanto aos seus objetivos - Exploratória ou Descritiva ou Exploratória-descritiva; e Quanto aos seus procedimentos técnicos - Pesquisa bibliográfica e Pesquisa documental e Pesquisa experimental e Levantamento de dados e Estudo de caso e Pesquisaação e Pesquisa-participante e Outros: Exploratória e Pesquisa de campo. Para todos os casos o item: Não informado completou o levantamento, a medida que coube aos pesquisadores não interferir subjetivamente nos textos, contabilizando apenas o que os textos declaravam objetivamente. Além da quantificação de cada dado este estudo reuniu as palavras chave de cada trecho encontrado para fazer uma análise a partir da produção de painéis de palavras.

O quarto passo foi o de tabular e produzir os gráficos oportunizando a leitura direta e clara dos dados coletados. Assim como no desenvolvimento dos painéis de palavras para cada trecho dos textos encontrados, utilizando o aplicativo online: http://www.wordle.net. 


\section{QUESTÕES DE PESQUISA, OBJETIVOS E HIPÓTESES NAS PRODUÇÕES DO PÓS-DESIGN UFSC ATÉ 2012:}

O texto de toda intervenção científica deve ser "claro, preciso, não deixando margem a dúvidas" (Lakatos; Marconi, 1992, p. 81) quanto a sua linguagem, mas também quanto a sua temática, mais especificamente ao problema que o mesmo propõe resolver, a medida que "ela esclarece a dificuldade específica com a qual se defronta e que se pretende resolver por intermédio da pesquisa" (Lakatos; Marconi, 1992, p. 81); que normalmente se resume na questão de pesquisa. A partir do problema bem definido, pode-se formular o objetivo, que ao delimitar o tema da intervenção liga-se a uma visão global e abrangente do mesmo, indo ao caráter mais concreto da abordagem. O tema de pesquisa, individualizado e especificado na problematização e na questão de pesquisa necessita de uma resposta "provável, suposta e provisória" (Lakatos; Marconi, 1992, p. 104), ou melhor, hipótese. Estes três pontos constroem a estrutura básica do projeto de pesquisa, que norteará toda o desenvolvimento de pesquisa até a produção do texto final, dando ao mesmo a segurança de se mostrar finalizado a medida que se responda ou não a questão norteadora, a partir de seus objetivos dentro do forma hipoteticamente respondido. Tais pontos aparecem assim nas produções do programa de Pós-Design UFSC até 2012:

Quadro 1 - Questão, Objetivo e Hipótese no Pós-Design UFSC até 2012.

\begin{tabular}{|c|c|c|c|c|c|c|}
\hline CENSO & \multicolumn{2}{|c|}{ Questăo } & \multicolumn{2}{c|}{ Objetivo } & \multicolumn{2}{c|}{ Hipótese } \\
\hline & S & N & S & N & S & N \\
\hline 52 & 36 & 16 & 52 & 0 & 5 & 47 \\
\hline
\end{tabular}

FONTE: Autores

Enfatiza-se no Quadro 1 que das 5 hipóteses confirmadas duas ofereceram textos nominando-a com terminologias diferentes, uma como "resultado esperado" e outra como "pressupostos", além de que na questão de pesquisa, das 36 que declararam textualmente, grande parte apresentou mais de uma questão. De forma a melhorar a leitura dos dados o gráfico abaixo foi construído: 
Gráfico 1 - Questão, Objetivo e Hipótese no Pós-Design UFSC até 2012.

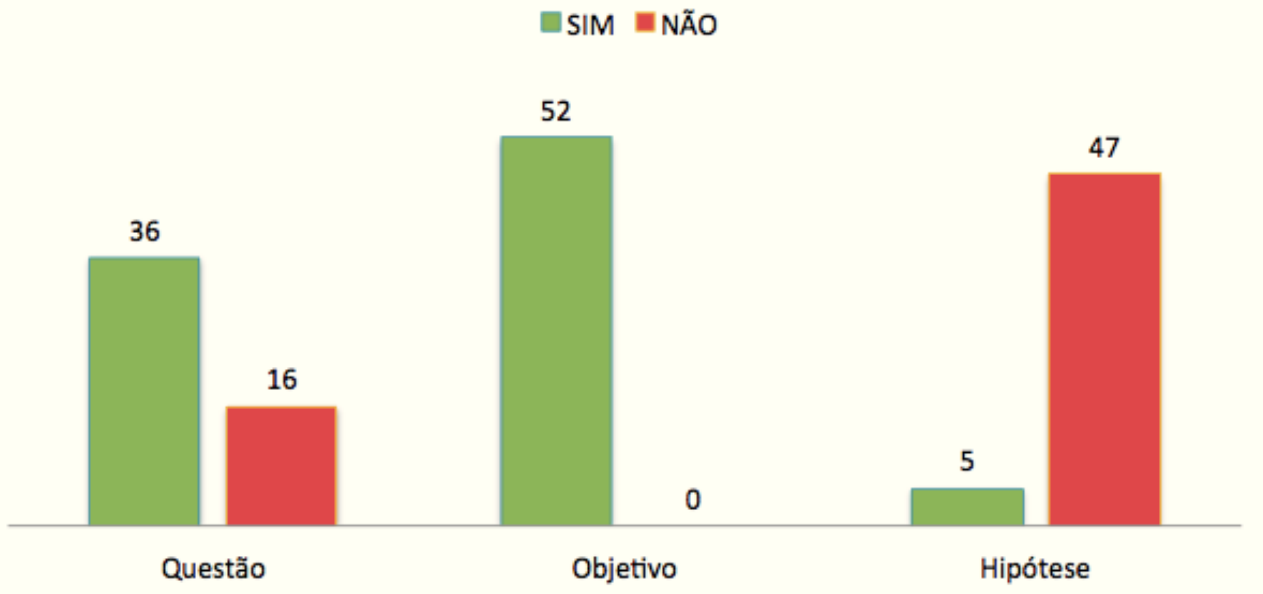

FONTE: Autores

Além da leitura quantitativa dos dados tabulados o estudo produziu, como descrito no terceiro e quarto passo da delimitação da pesquisa, o painel de palavras oferecendo um panorama visual dos principais termos que aparecem na formulação de cada questão, objetivo e hipótese, quando declaradas nas produções do programa de Pós-Design UFSC até 2012, que assim são apresentados:

Figura 1 - Painel de palavras das 5 Hipótese declaradas no programa de Pós-Design UFSC até 2012.

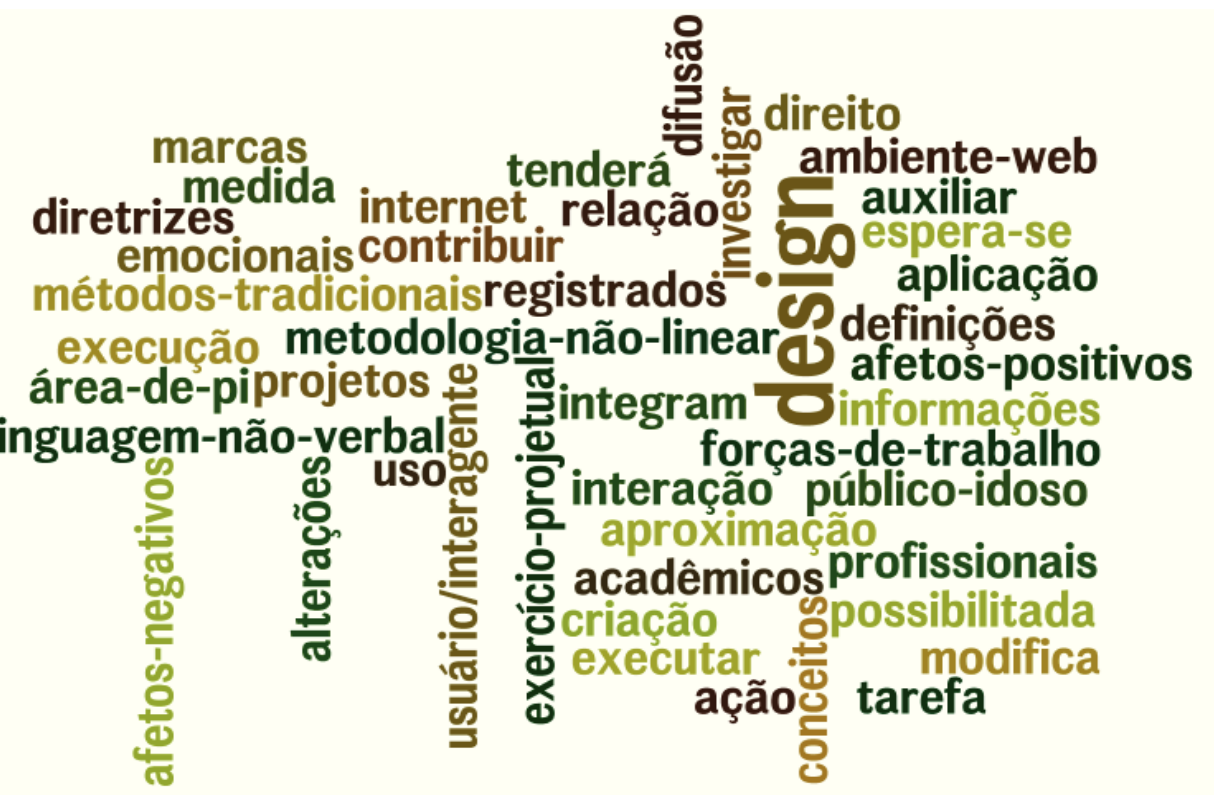

FONTE: Autores 
Como o universo de produções que apresentam hipóteses é pequeno, não houve termos repetidos, ou uma tendência das hipóteses dentro do programa, por mais que todos os termos apresentado neste painel (Figura 1) estão relacionados diretamente ao design e ao campo de pesquisa científica, oferendo, dentro do possível um panorama coerente destas duas áreas.

Porém quando tomadas as questões das pesquisa, quando declaradas o panorama apresentado pelo painel de palavras já mostra certa tendência, como ilustra a Figura 2:

Figura 2 - Painel de palavras das 36 questões declaradas no programa de Pós-Design UFSC até 2012.

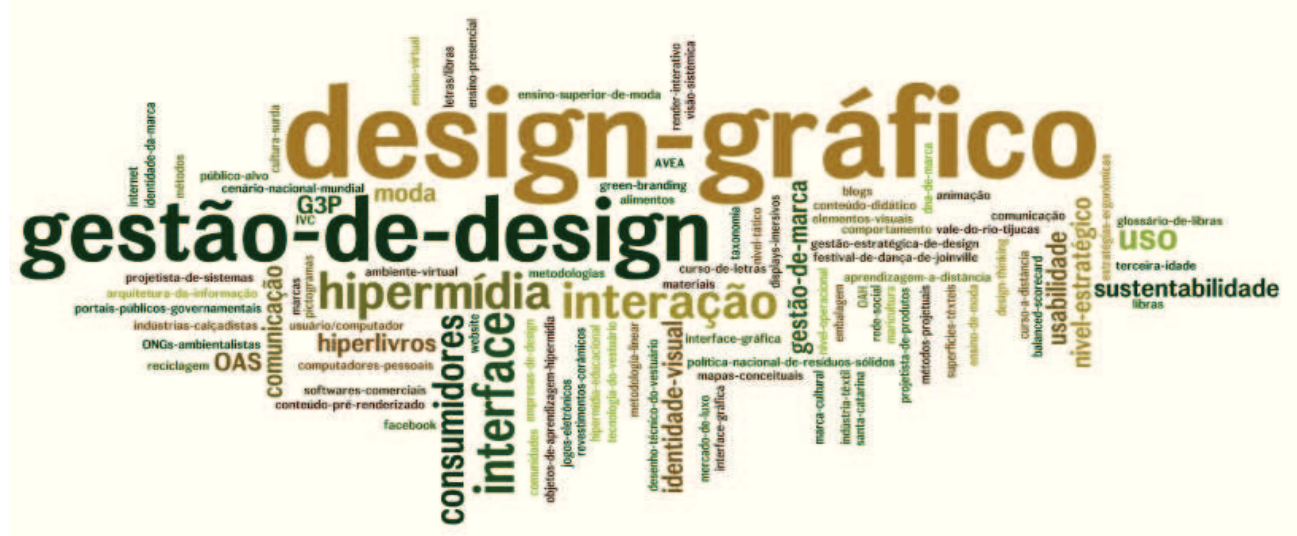

FONTE: Autores

Das 52 produções analisadas, 36 delas apresentam questões de pesquisa que oferecem as tendências dos temas pesquisados e defendido no Programa de Pós-Design UFSC até 2012, onde se destacam o tema "design gráfico"; "gestão de design". Com menor ênfase os termos, "Hipermídia"; "interação"; "interface"; e "uso"; oportunizam um registro das abordagens das pesquisas a partir de suas linhas de pesquisa: Hipermídia Aplicada ao Design e Gestão Estratégica do Design.

O mesmo panorama, de forma lógica se mostra quando tratados os objetivos de cada produção, ainda mais quando nesta quantificação o estudo obteve de todas as produções declaradas no CAPES. Das 52 produções do Programa de Pós-Design UFSC, qualificadas, defendidas e aprovadas até 2012 a tendência temática dos objetivos se apresenta ilustrada na Figura 3: 
Figura 3 - Painel de palavras dos 52 objetivos declarados no programa de Pós-Design UFSC até 2012.

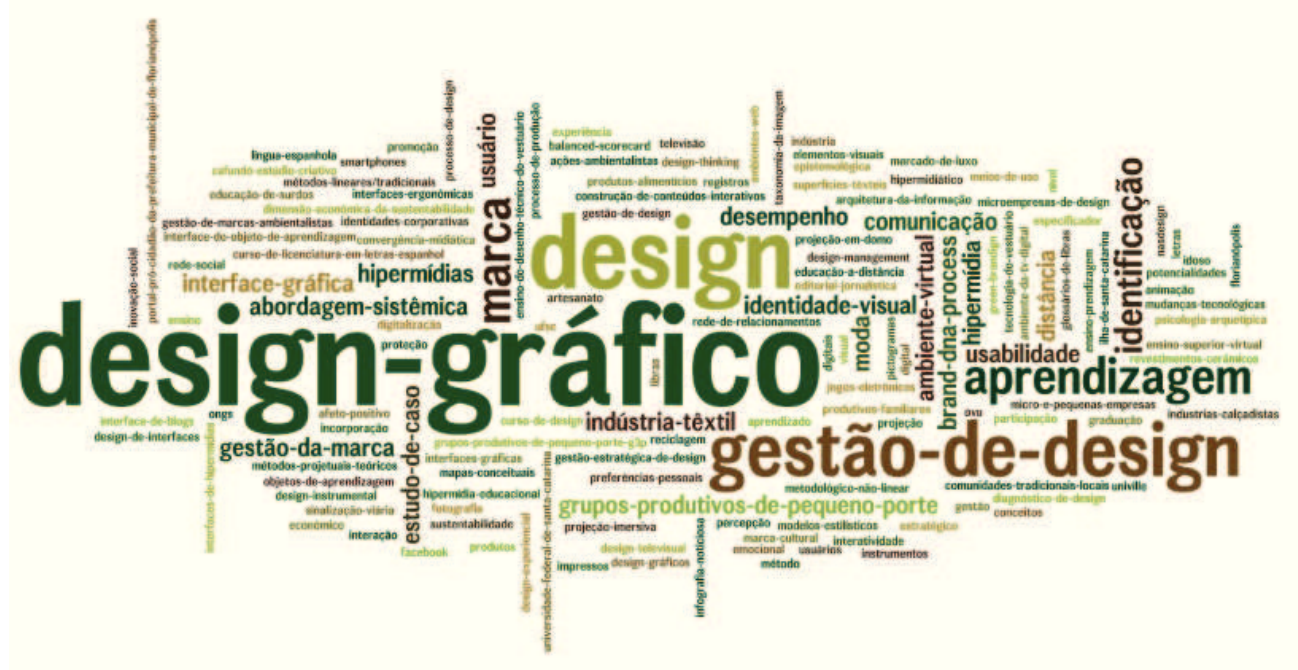

FONTE: Autores

O painel de palavras quanto aos objetivos de cada produção (Figura 3) explicitou os mesmos termos declarados pelas questões: "design gráfico"; "design; e "gestão de design"; havendo destaque aos termos, "marca"; e "aprendizagem". Estes termos apresentam a tendência temática dos objetivos, espelhando coerentemente as questões de pesquisa. Mas por se tratar de objetivos o verbos ganham destaque, desta forma foi desenvolvido um painel dos verbos dos objetivos gerais de cada produção, como ilustra a Figura 4:

Figura 4 - Painel de palavras com os verbos dos 52 objetivos declarados no programa de Pós-Design UFSC até 2012.

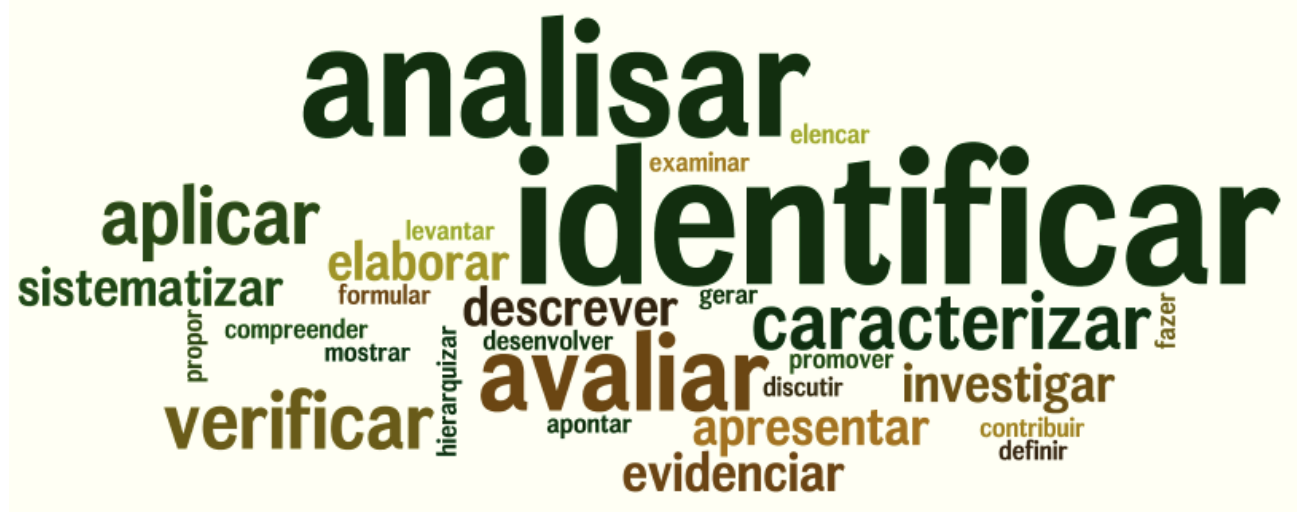

FONTE: Autores 
Os principais verbos utilizados nas produções do Programa de PósDesign UFSC são o "identificar" e "analisar", ficando verbos como "avaliar"; "caracterizar"; e "aplicar" em segundo plano. A utilização de tais verbos direciona os procedimentos de pesquisa classificando-os dentro de uma determinada abordagem, como será apresentado a seguir.

\section{A CLASSIFICAÇÃO DAS PESQUISAS DO PÓS-DESIGN UFSC ATÉ 2012:}

A pesquisa científica está pautada num conjunto de ações que visam atingir os objetivos pretendidos, respondendo as questões iniciais que a problematizam, podendo em muito casos levantar hipóteses que devem ser confrontadas ao final. Para tanto estas pesquisas precisam procedimentos racionais e sistemáticos, com base em uma metodologia de pesquisa que se classifica quanto a sua natureza, quanto a sua forma de abordagem, quanto aos seus objetivos e quanto aos seus procedimentos técnicos para a coleta, análise e síntese de informações e dados.

Aos programas de pós-graduação stricto sensu as pesquisas resultam em um estudo científico com temática única e delimitada. Evidenciando o conhecimento existente e a capacidade sistematizada de domínio do tema abordado. Quanto a originalidade e ineditismo a obrigação fica mais ao doutorado (Tese). Mas tanto o doutorado quanto o mestrado se constroem como programas científicos a medida que definem, utilizam e evidenciam uso de procedimentos técnicos dentro das classificações necessárias à abordagem do tema escolhido. Este estudo, em seu segundo objetivo identificou e quantificou tais procedimentos a partir das declarações de cada uma das 52 produções analisadas. E o resultado se mostra desta maneira: 
Gráfico 2 - Classificação quanto a Natureza das pesquisas no PósDesign UFSC até 2012.

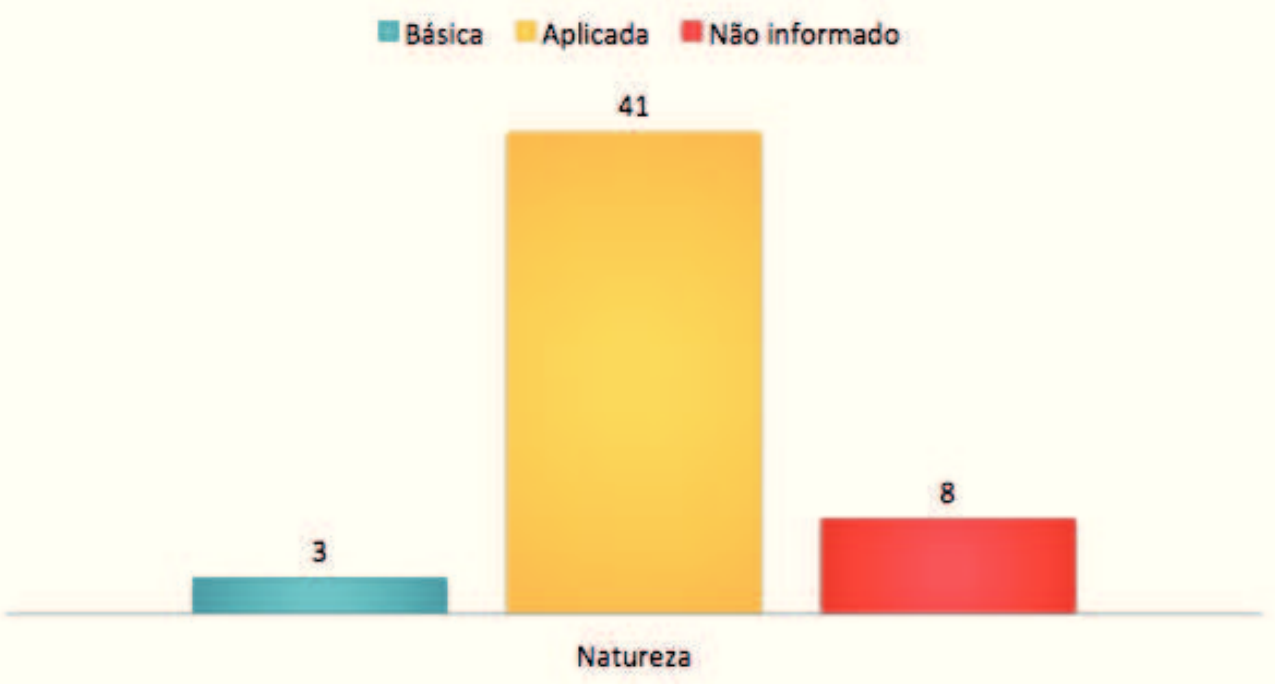

FONTE: Autores

Quanto a natureza 41 das produções declararam ser aplicadas, objetivando gerar dados (material) para aplicação prática e dirigidos à soluções de problemas específicos. 3 declararam ser básicas, gerando conhecimentos novos se a previsão de sua aplicabilidade prática. E 8 não deixaram claro esta informação.

Gráfico 3 - Classificação quanto a Forma de abordagem das pesquisas no Pós-Design UFSC até 2012.

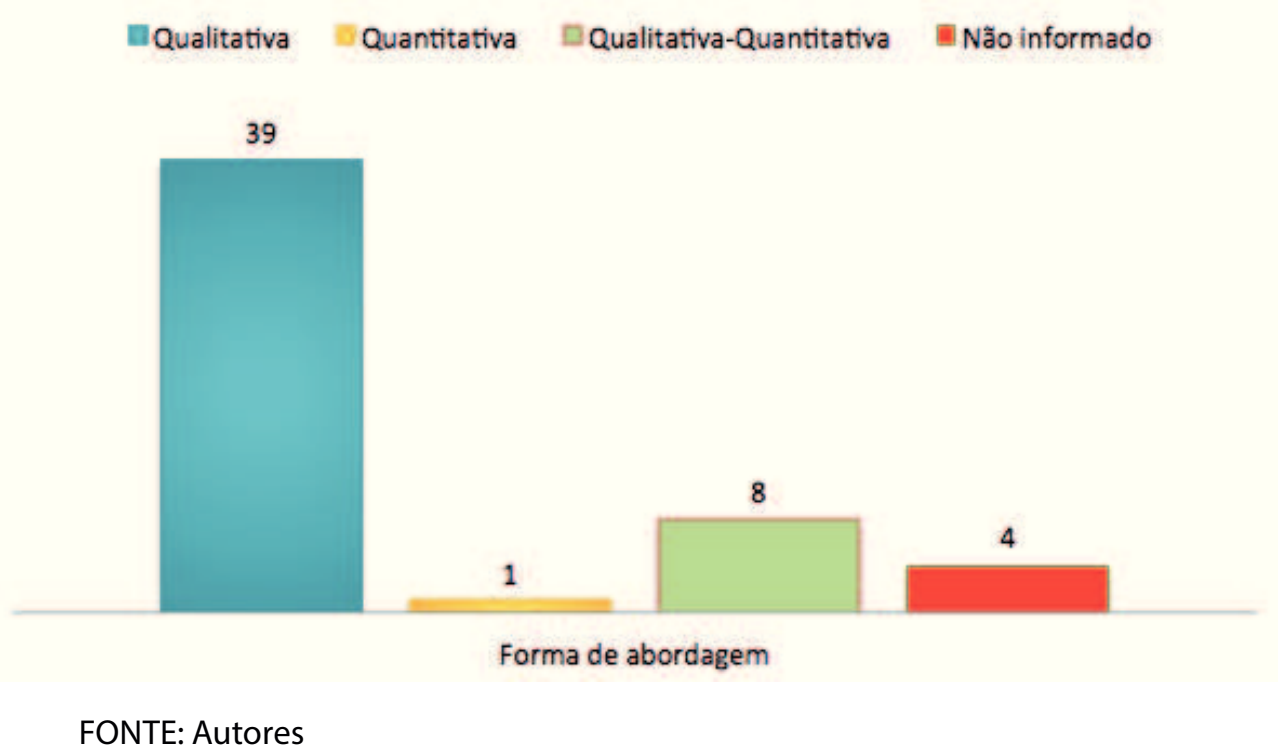


Quanto a forma de abordagem 39 das produções declararam ser qualitativas onde o pesquisador colhe informações, examina cada caso separadamente e tenta construir um caso geral da situação. Como num quebra-cabeça, o pesquisador junta as pecas até a compreensão geral do problema. O método qualitativo, em geral, é menos estruturado, proporcionando assim um contato mais longo e flexível entre o pesquisador e o entrevistado. Possibilitando ainda lidar com informações mais subjetivas, amplas e com maior riqueza de detalhes (DIAS, 2000). Ainda quanto a forma de abordagem 8 declararam ser qualitativas e quantitativas estruturando um pouco mais o método de abordagem, assegurando, em determinados momentos um contato mais breve e inflexível entre o pesquisados e o entrevistado. Quanto a forma de abordagem, somente uma declarou ser quantitativa traduzindo em números informações e dados durante a obtenção, análise e síntese. Possibilitando lidar com maior objetividade, oportunizando o uso de técnicas estatísticas. Finalizando quanto a forma de abordagem 4 produções não deixaram clara esta informação.

Gráfico 4 - Classificação quanto aos Objetivos das pesquisas no PósDesign UFSC até 2012.

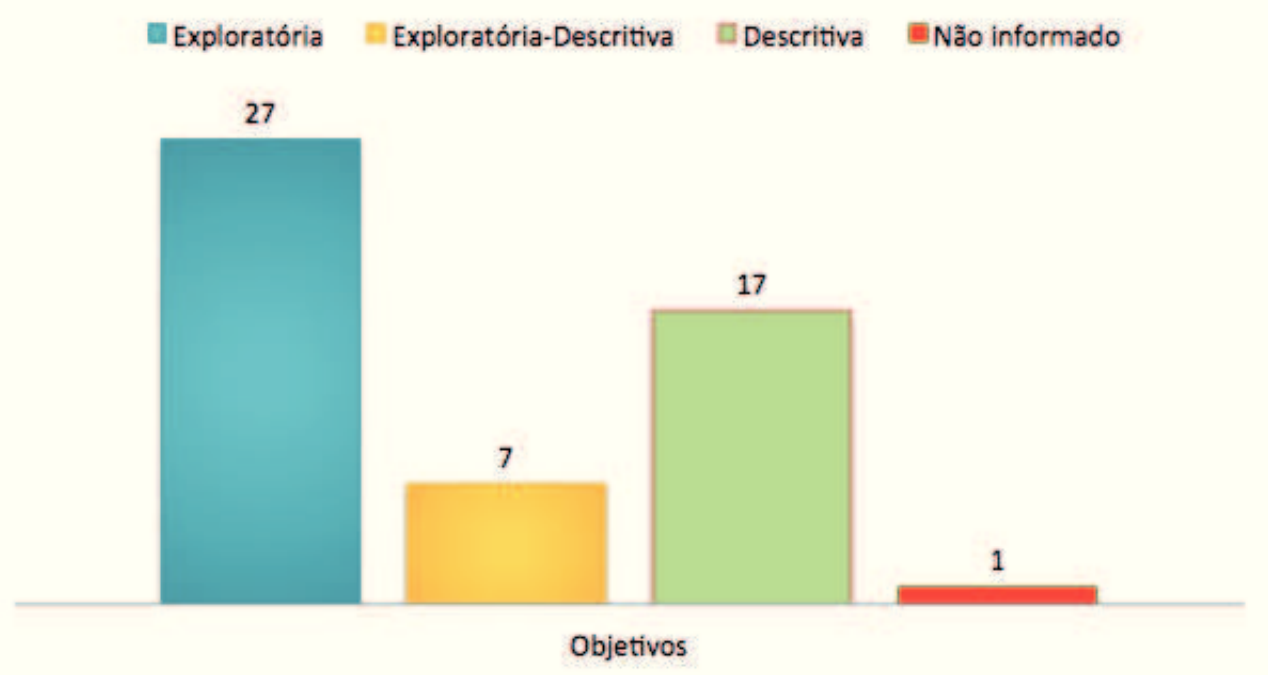

FONTE: Autores

Quanto aos objetivos 27 declararam ser pesquisas exploratórias, onde há o intuito de fazer um levantamento de materiais para uma investigação. 
Minayo e Sanches (1993) consideram que o estudo exploratório permite unir as vantagens dos aspectos qualitativos das informações e a possibilidade de quantificá-los, sendo que essa associação se da por complementaridade. Dez a menos, 17, declaram, quanto aos objetivos, ser pesquisas descritivas, cujo objetivo é descrever as características de uma população, de um fenômeno ou de uma experiência. Esse tipo de pesquisa estabelece relação entre as variáveis no objeto de estudo analisado. Variáveis relacionadas à classificação, medida e/ou quantidade que podem se alterar mediante o processo realizado.

Quando comparada à pesquisa exploratória, a única diferença que podemos detectar é que o assunto já é conhecido e a contribuição é tão somente proporcionar uma nova visão sobre esta realidade já existente. Sete (7) declararam suas pesquisas como exploratórias e descritivas ao mesmo tempo. E apenas uma (1) não deixou claro tal informação.

Gráfico 5 - Classificação quanto aos procedimento técnicos das pesquisas no Pós-Design UFSC até 2012.

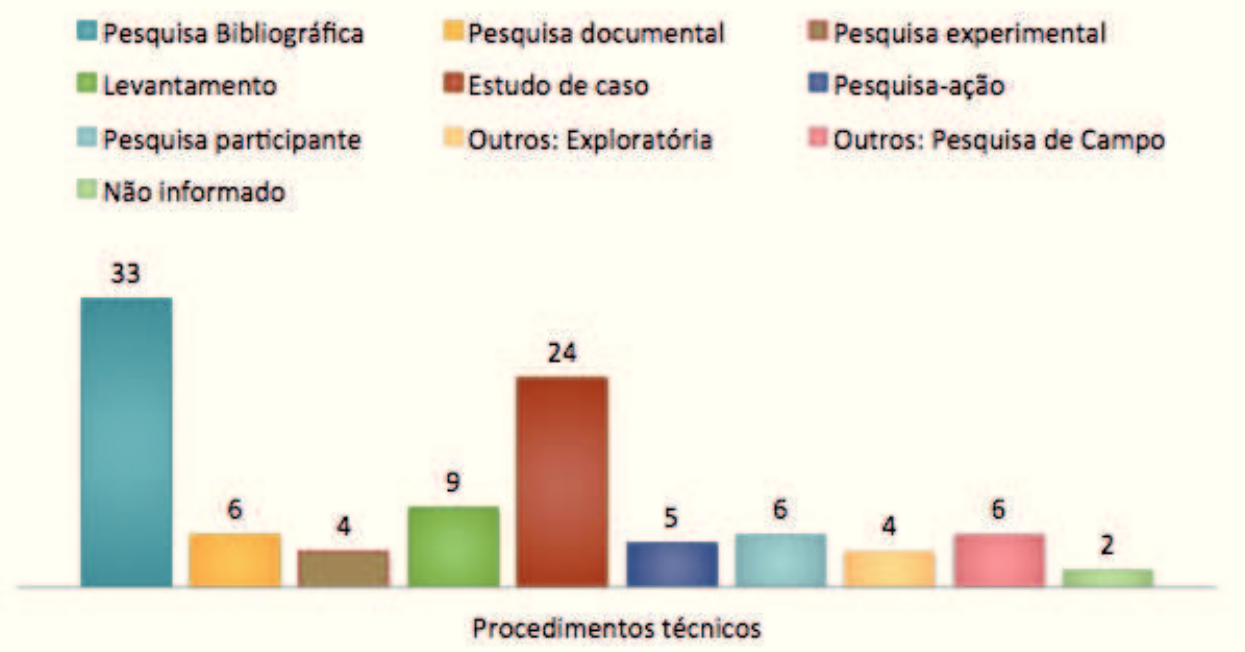

FONTE: Autores

Diferente da natureza, da abordagem e dos objetivos onde as pesquisas devem optar um caminho. Nos procedimento técnicos as pesquisas podem optar por um ou mais de um, desta forma a leitura do Gráfico 4 deve tomar o total de 52 para cada procedimento, ficando assim descrito: Das 52, 33 declararam a pesquisa bibliográfica como procedimento técnico, 
servindo-se de base teórica para a construção do trabalho e para nortear o trabalho de campo. Das 52, 24 declararam o estudo de caso, essencial para se examinar acontecimentos contemporâneos nos quais não se pode manipular comportamentos relevantes. Segundo Yin(2005) o diferencial do estudo de caso é a sua capacidade de lidar com a ampla variedade de evidências, documentos, artefatos entrevistas e observações, além do que pode estar disponível no estudo histórico convencional. Das 52, 9 utilizaram, de forma declarada o levantamento (de dados) como procedimento técnico envolvendo a interrogação direta de pessoas foco do tema abordado. Das 52,6 declararam a pesquisa documental, elaborando com base em materiais com pouco, ou sem nenhum, tratamento analítico. Das 52, 6 declararam, como procedimento técnico, a pesquisa participante estabelecendo contato direto com os sujeitos da pesquisa. Das 52,5 declaram a pesquisa-ação considerada uma estratégia de pesquisa agregando vários métodos de pesquisa social, com os quais se estabelece uma estrutura coletiva, participativa e ativa ao nível da captação de informação. O que significa que não há uma limitação quanto ao uso de ferramentas de coleta e análise de dados em pesquisaação. Das 52, 4 declararam a pesquisa experimental procedimento técnico devendo ter como característica estudar as relações de causa e efeito e a manipulação criteriosa de variáveis, com o intuito de determinar influencias. Das 52, 6 declararam a pesquisa de campo e 4 exploratória. E, por fim, das 52, 2 não deixaram claro tal informação, conforme demostrado no Gráfico 5.

\section{CONSIDERAÇÕES FINAIS:}

Os dados apresentados nesta pesquisa oportunizam cruzamentos e reflexões importantes para uma avaliação do que vem sendo produzido, qualificado, defendido e aprovado no programa de Pós-Design UFSC até 2012, porém este estudo não tem esta pretensão mas contribui para, a medida que apresenta a identificação e quantificação da ocorrência de questões, objetivos e hipóteses nas produções do Pós-Design UFSC, assim como a classificação (quantificada) de suas pesquisas, objetivos centrais deste estudo.

Distanciando-se das questões de valor o que se poder concluir após a realização deste estudo é a constatação de uma falta de formalização das produções visando a clareza que contribua para a identificação das informações buscadas nesta pesquisa, afinal estas não só delimitam o 
intervenção feita, quanto consolidam a cientificidade de tal intervenção. Outro resultado a solicitação de uma cobrança maior nas produção das versões finais, necessitando um revisão criteriosa no momento de disponibilizar, em alguns casos o nome publicado na Capes, não é o mesmo que esta no sistema Pergamum, da Biblioteca Universitária da UFSC, dificultando o acesso ao material completo.

\section{REFERÊNCIAS}

BARROS, Aidil de Jesus P. de. Projeto de pesquisa: propostas metodológicas. Petrópolis, RJ: Vozes, 2012.

CAPES - www.capes.gov.br Acesso em 27/Ago./2014.

DIAS, Cláudia Augusto. Grupo focal: técnica de coleta de dados em pesquisas qualitativas. Informação e sociedade. Paraíba, v. 10, n. 2, p. 141-158, 2000.

FIALHO, Francisco A. P.; BRAVIANO, Gilson; SANTOS, Neri dos. Métodos e técnicas em ergonomia. Florianópolis: Edição dos autores, 2005.

LAKATOS, Eva M.; MARCONI, Marina de A.. Metodologia do trabalho científico: procedimentos básicos, pesquisa bibliográfica, projeto e relatório, publicações e trabalhos científicos. São Paulo: Atlas, 1992.

SEVERINO, Antônio J. Metodologia do trabalho científico. São Paulo: Cortez, 2002.

MINAYO, Maria C. De S.; Sanches, ODÉCIO. Quantitativo-Qualitativo: Oposições ou complementaridade? Em: cadernos de saúde pública. Rio de Janeiro: Editora Fiocruz,9(3), p. 239-248,1993.

YIN, R. K. Estudo de caso: Planejamento e métodos. 3Ed. Porto Alegre: Bookman,2005.

Ricardo Triska é graduado em Ciência da Computação pela Universidade Federal de Santa Catarina (1984), mestrado em Ciência da Informação pela Universidade Federal do Rio de Janeiro (1993) e doutorado em Engenharia de Produção (Área de concentração Ergonomia) pela Universidade Federal de Santa Catarina (2001). Professor associado 1 da Universidade Federal de Santa Catarina, lotado no Departamento de Expressão Gráfica, compõe o quadro de Docentes Permanentes do Programa de Pósgraduação em Design e Expressão Gráfica, nível mestrado, e doutorado, e do curso de Bacharelado em Design. Desenvolveu projetos na área de Ciência da Informação, com ênfase no processo de Transferência da 
Informação, atuando nas áreas de planejamento de produtos, serviços e sistemas de informação; automação de bibliotecas e bibliotecas digitais. Também desenvolveu projetos nas áreas de gestão do conhecimento e aprendizagem organizacional. Seus projetos atuais se concentram em Linguagem Subliminar, Processos Corporativos, Design de Interface e no Design da Informação. Coordenador da Área de Arquitetura, Urbanismo e Design junto à CAPES(2011-2014).Reconduzido para o período 2014-2017. Conselheiro do Conselho Técnico Científico de Ensino Superior / CAPES (2014-2017).

Currículo Lattes: http://buscatextual.cnpq.br/buscatextual/visualizacv. do?id=K4794275A4

João Carlos Vela é graduado em Design de Produto pela Universidade Tuiuti do Paraná - UTP- (2001), Especialista em Ensino da Expressão Gráfica pela Universidade do Paraná - UFPR (2004), Mestre em Educação, pela Universidade Regional de Blumenau - FURB (2009). Foi professor substituto da Universidade Federal de Santa Catarina -UFSC nas disciplinas de Modelagem 3D e Representação Gráfica entre os anos de 2011 e 2012. Atualmente é professor e Chefe do Departamento de Design da Universidade da Região de Joinville -(UNIVILLE) e doutorando em Design do programa de Pós Design da Universidade Federal de Santa Catarina -UFSC.

Currículo Lattes: http://buscatextual.cnpq.br/buscatextual/visualizacv. do?id=K4732453E5

Jorge Elias Dolzan é doutorando em Gestão do Design no Pós-Design UFSC. Mestre em Ciências da Linguagem. Especialista em Ensino de Artes Visuais e Bacharel em Desenho Industrial (habilitado em Projeto de Produto e Programação Visual). Atuou como Diretor de Ensino do Município de São

Recebido em: 23/09/2014; Aceito em: 01/12/2014.

Esta obra foi licenciada com uma Licença Creative Commons.
José (2013) e Pró-reitor de Pós-Graduação na Estácio de Santa Catarina (2013-2014). Professor dos cursos de Design de Moda, Aqruitetura e Urbanismo e Comunicação Social da Estácio de Santa Catarina.

Currículo Lattes: http://buscatextual.cnpq.br/buscatextual/visualizacv. do?id=K4779904H1 


\section{ERRATA}

Também incorpora o corpo autoral do artigo a pesquisadora a seguir:

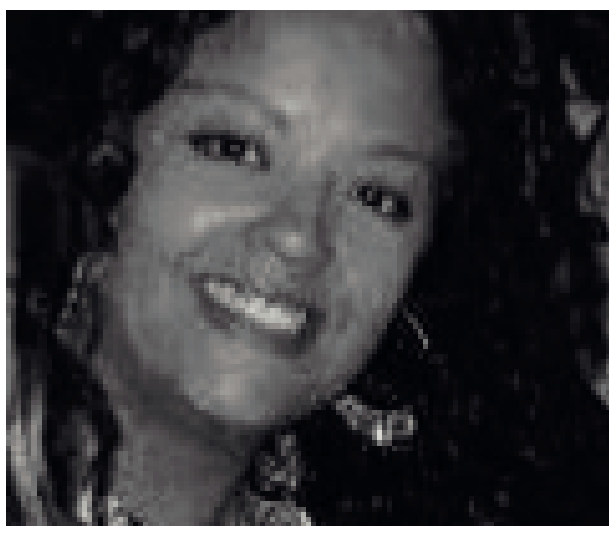

Juliane Marçal da Silva Prodanov

Mestranda do Programa de Pós-Design UFSC.

Formada pela Universidade Federal de Santa Catarina em design com habilitação em produto. 